\begin{abstract}
Submitted: 03.09.2018 Accepted: 11.11.2018 Published: 31.12 .2018

\section{Recommendations for ultrasound examination in ophthalmology. Part I: Ultrabiomicroscopic examination}

\author{
Jacek Kosmala ${ }^{1}$, Iwona Grabska-Liberek¹, \\ Rimvydas Stanislovas Ašoklis²,3
}

${ }^{1}$ Department of Ophthalmology, Medical Centre of Postgraduate Education, Professor Witold Orlowski Independent Public Clinical Hospital, Warsaw, Poland ${ }^{2}$ Vilnius University, Faculty of Medicine, Vilnius, Lithuania

${ }^{3}$ Center of Eye Diseases in Vilnius University Hospital Santaros Klinikos, Vilnius, Lithuania Correspondence: Jacek Kosmala, Klinika Okulistyki CMKP, Samodzielny Publiczny Szpital im. prof. W. Ortowskiego, ul. Czerniakowska 231, 00-416 Warszawa, Poland
\end{abstract}

Keywords ultrasound biomicroscopy (UBM), ophthalmic indications and contraindications for UBM, standards of conduct during the test

DOI: $10.15557 / J o U .2018 .0050$

\begin{abstract}
Range of ultrasounds used in medical imaging is between 2 and $80 \mathrm{MHz}$. The highest frequencies are applied in medical imaging of an anterior segment of an eyeball. This paper covers the newest method of ultrasound imaging - an ultrabiomicroscopic examination. Its name reflects resolution which has so far been unavailable, and which allows for imaging a structure of the examined tissues. The article includes basic information about the structure and principles of operation of ultrabiomicroscopic examination tools. Moreover, its position among other methods for echographic examination of an eyeball was determined. Examination techniques and the role of standards of conduct at each stage of a diagnostic procedure were discussed. A role of insufficient cooperation between constructors of new ultrasonographic diagnostic tools and software IT specialist with the users of these tools, which results in the lack of consistency between the components of these sets was emphasized. Based on long term experience in ultrabiomicroscopic examinations, the authors shared observations on practical aspects of this method. Finally, indications and contraindications for ultrabiomicroscopic diagnostics were listed. Introduction of an ultrahigh frequency ultrasound probe allowed for the visualization of an post-iridial area of an anterior segment of an eyeball - an area whose diagnosis is impossible with other diagnostic methods. A wide spectrum of diagnostic indications, which covers both diseases and development anomalies of an anterior segment of an eyeball, confirms a special meaning of this method.
\end{abstract}

An ultrabiomicroscopic examination is a contact, non-invasive method for imaging of tissues in an anterior segment of an eyeball. It is conducted in topical anesthesia with a probe which emits ultrasounds of very high frequency ranging from 35 to $60 \mathrm{MHz}^{(1-3)}$. This examination, like an ultrasound examination in presentations $\mathrm{A}$ and $\mathrm{B}$, does not cause any medically proven side effects which would be harmful to patient's health ${ }^{(4)}$. Scientists who contributed most to the development of this imaging method at the turn of 1980s and 1990s, were C.J. Pavlin, M.D. Sherar i F.S. Foster ${ }^{(2)}$.

A real-time image displayed on the screen is a two-dimensional surface which presents a grey-scale ultrasonographic profile of the examined structures. Each frame from the conducted examination may be analyzed in terms of quality and quantity. Image resolution with an ultrabiomicroscopic probe of $50 \mathrm{MHz}$ frequency is ten times higher (axial resolution/transverse resolution - ca. 25/50 $\mu \mathrm{m})^{(1)}$ than of an image obtained with a $12 \mathrm{MHz}$ ultrasonographic probe in presentation B. Much higher resolution of the examination is, however, accompanied by its far lower range - for modern probes of $50 \mathrm{MHz}$, it is only as much as $8-10 \mathrm{~mm}$. Nevertheless, such range on the examination axis, combined with the scanned image width exceeding $12 \mathrm{~mm}$ on a transverse axis, allows for imaging the whole anterior segment of an eyeball in one scan. Contrary to electromagnetic waves, ultrasound waves freely penetrate eyeball structures that are opaque for light, which makes imaging 


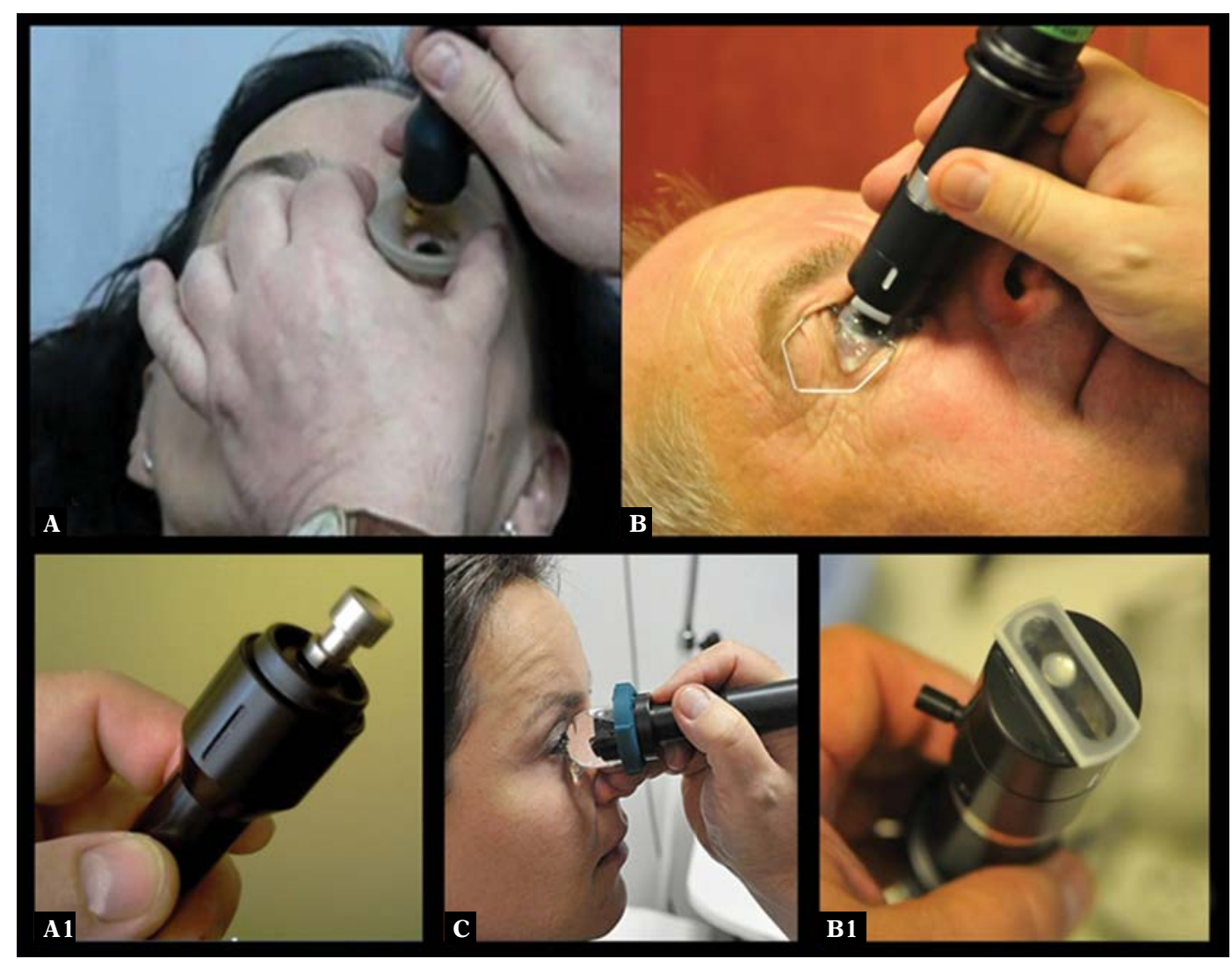

Fig. 1. UBM examination with a sector probe (A) and a linear probe (B). A1. Head of a sector probe. B1. Head of a linear probe (with a frame closing an immersion chamber filled with liquid. C. Examination with a sector probe with ClearScan balloon technique

an anterior segment of an eyeball in post-iridial and subscleral circum-limbal areas possible without obstacles ${ }^{(1-3)}$.

Ultrabiomicroscopic imaging of an anterior segment of an eyeball is carried out with mechanical probes. In such heads, an ultrasound beam is produced by a mobile ultrasound converter equipped with an acoustic lens. The converter, located at the front of the probe and moving in one plane, emits ultrasound waves and simultaneously receives wave reflections from various levels of the examined structure, and transforms them in an alternating electric potential. After amplification and a digital analysis, the potential gives an ultrasound image of an examined tissue ${ }^{(1)}$. The plane of a moving converter determines the plane of an examined image. An acoustic lens in the converter focuses an ultrasound beam and thus determines the distance between the highest imaging resolution and the probe's tip $^{(1)}$. Based on the trajectory of the converter's movement, there are sector probes (pendulum movements), and linear probes (linear movements).

Air is a poor conductor of ultrasound waves, which makes it necessary to provide environment that conducts ultrasounds well between a moving ultrasound converter and an eyeball surface during the examination. It should be taken into consideration that in this case, due to little penetrability of ultrahigh frequency ultrasounds, it is impossible to use a closed case made of plastic material filled with a liquid, as it is possible in mechanical probes in presentation $\mathrm{B}$.

In sector probes (Fig. $1 \mathrm{~A} 1$ ), this problem was solved by equipping a diagnostic tool with an immersion chamber (made of silicone or plastic) which was installed in a palpebral fissure of an examined eye and filled with saline solution (a medium which generates images of the highest quality) before the examination ${ }^{(2)}$. A mobile tip of a probe is immersed in the liquid in an immersion chamber (Fig. 1 A). Such a solution provides good conduction of ultrasound waves with a simultaneous possibility of a smooth transfer of the image's highest resolution field (which develops in the focus of an acoustic lens) by approaching the probe's head and moving it away from an eyeball. A limitation to this method is the fact that the patient's head must be set horizontally (in a lying or sitting position) during an examination, as well as lack of a possibility to examine circum-limbal areas of sclera, which do not fit an immersion chamber (especially when hard plastic immersion chambers are used). In the recent years, this problem has been solved with ClearScan balloon technology which enables examination in a random location without an open immersion bowl ${ }^{(5)}$ (Fig. 1 C).

Linear probes are equipped with their own immersion chambers (Fig. 1 B1), in which an ultrasound converter moves linearly. When an immersion chamber is filled with distilled water, an open forefront of the probe is closed 
with a disposable plastic frame covered with thin foil. High stiffness ultrasound gel is applied as a medium between a probe and an eye, which allows for the maintenance of constant contact between a probe and an eye when focusing an image in the examination. Eyelids of an examined eye are stabilized with an eyelid retractor (Fig. 1 B).

An important element of the probe is a marker placed at its front; it determines a plane of the ultrasound converter's movement. This marker allows for the direction of an image of a given plane of an ultrasound profile on a screen. In USG examination in presentation $B$, in all available ultrasound scanners, a marker directs image from an upper edge of the screen. Producers of ultrabiomicroscopes do not follow one scheme and the marker may direct an image both from the left and from the right edge of the screen ${ }^{(3)}-$ such information should be provided in a manual.

During an examination, three basic probe settings are used: an axial setting, a meridional setting ration and a latitudinal setting. In the case of meridional and latitudinal ones, Pavlin et al. suggested a different setting of a marker than the one in presentation B. However, this suggestion was not acknowledged in the proposed schemes of reports on examinations in currently produced ultrasound tools which include presentation A, B and UBM. In the description of UBM examination, only schemes with a marker recommended in presentation B are available, which does not favor compliance with the standard proposed by Pavlin et al. in terms of positioning of a probe's marker during an ultrabiomicroscopic examination.

"Friendly" computer software, which allows for a qualitative and quantitative analysis images obtained in the examination and facilitates report preparation, is crucial for the people in charge of the examinations. Lack of norms which determine "computer tools" in this area results in the fact that every producer equips an ultrasound diagnostic tool in accordance with their own view, with a more or less extended software.

A biomicroscopic examination is a demanding method. An examination field of a few millimeters located nearby a moving ultrasound converter, requires high precision of an examiner. Selection of proper scans when determining a progression of cancerous changes, searching small foreign bodies in the tissues of an anterior segment of an eyeball, or in order to assess the effects of various operating procedures, requires an experienced investigator. Therefore, basic guidelines should be followed. In order to obtain a clear image, a probe should be set in such a way that an axis of emitted waves is maximally perpendicular to the surfaces of the examined intrabulbar structures. Image of the highest resolution is in the focus point of an acoustic lens. Having located the searched structure of an anterior segment of an eyeball, it is possible to increase image resolution in this area by changing the distance between an ultrasound probe's forefront and an eyeball. In an examination with a mechanical probe, an image's plane is created when an ultrasound converter is moving (pendually or linearly). A single movement of the converter equals one frame of a movie which documents the examination. Frequency of converter's movements allows for the acquisition of a smooth enough examination image on the screen. It ought to be remembered that too fast movements of the probe over an examined area, or sudden changes of a setting angle may result in an incorrect record or "losing" fragments of the image of an examined structure. It is also important to maintain stable conditions in repeated examinations of the same patient. Various illumination of an examination field changes pupil's width, which may result in the change of width of an infiltration angle, and shape and size of pathological changes in an iris, due to the changes in iris' surface tension. The easiest method for solving this problem is providing stable artificial illumination during a UBM examination, regardless of the degree of daylight ${ }^{(3)}$.

Sterilization of UBM probes before and between examinations of various patients is another issue. Each producer provides their own sterilization scheme adjusted to the probe's system (with its own immersion chamber and an additional immersion bowl in a set), and to the type of materials of which its components are made. Following the procedure standards during sterilization is crucial due for patients' health and keeping the producer's warranty.

To sum up, such standard procedures are followed during an ultrabiomicroscopic examination:

1) sterilization of equipment;

2) anesthesia;

3) providing a possibility of an undisturbed flow of ultrasounds between a probe's converter and an eyeball's surface - depending on the type of a probe (open, closed);

4) registration of ultrasonographic profiles of the examined structures with the description of their location and orientation;

5) description of the examination.



Fig. 2. UBM examination of an anterior segment of an eyeball nearby an infiltration angle. Each anatomical structure visible in the space before and behind the iris 
It ought to be emphasized that unlike methods based on electromagnetic wave imaging, one of the basic indications for an ultrabiomicroscopic examination is the assessment of an anterior segment of an eyeball which covers both the space before and behind the iris ${ }^{(1-3)}$ (Fig. 2).

Indications for a UBM examination are:

- diagnostics of corneal, conjunctivitis and eyelid disorders ${ }^{(1,3,6-8)}$;

- disorders of an anterior segment of $\operatorname{sclera}^{(1,3,9,10)}$;

- disorders and malformations of an iris and a ciliary body ${ }^{(1,3,11-14)}$;

- tumors in an anterior segment of an eyeball with the assessment of their progression or regression ${ }^{(1,3,15-24)}$;

- changes in peripheral parts of retina and choroid and an anterior part of a vitreous humor ${ }^{(1,3,25,26)}$;

- posttraumatic changes in an anterior segment of an eyeball, including intraocular foreign bodies before and after surgery ${ }^{(1,3,27-30)}$;

- qualification for cataract surgery, assessment of a lens and its hangers system ${ }^{(1,3,31,32)}$;

- qualification for the implantation of posterior- and anterior-chamber's phakic and pseudophakic lenses with biometric measurements of an anterior segment of an eyeball $^{(1,3,33,34)}$;

- control over the setting of implemented intraocular lenses ${ }^{(1,3,35-38)}$;

- glaucoma $^{(1,3,39-47) \text { : }}$

- assessment of width and shape of an infiltration angle in differentiation of glaucoma type with quantitative measurements,

\section{References}

1. Pavlin CJ, Foster FS: Ultrasound Biomicroscopy of the Eye. Springer \& Verlag, New York 1995.

2. Dada T, Gadia R, Vengayil S, Agarwal A, Sihota R: Anterior Segment Imaging in Ophthalmology. Jaypee Brothers Medical Publishers, New Delhi 2008.

3. Kosmala J, Grabska-Liberek I (eds.): Ultrabiomikroskopia - zastosowanie w okulistyce. Przegląd przypadków klinicznych. Termedia, Poznań 2014.

4. Dębski R: Czy badanie USG może szkodzić? Przemyślenia własne. Postępy Nauk Medycznych 2008; 4: 235-239.

5. Bell NP, Feldman RM, Zou Y, Prager TC: New technology for examining the anterior segment by ultrasonic biomicroscopy. J Cataract Refract Surg 2008; 34: 121-125.

6. Kikkawa DO, Ochabski R, Weinreb RN: Ultrasound biomicroscopy of eyelid lesions. Ophthalmologica 2003; 217: 20-23.

7. Demirci H, Nelson CC: Ultrasound biomicroscopy of the upper eyelid structures in normal eyelids. Ophthal Plast Reconstr Surg 2007; 23: 122-125.

8. Al-Faky YH: Anatomical utility of ultrasound biomicroscopy in the lacrimal drainage system. Br J Ophthalmol 2011; 95: 1446-1450.

9. Shaikh SI, Biswas J, Rishi P: Nodular syphilitic scleritis masquerading as an ocular tumor. J Ophthalmic Inflamm Infect 2015; 5: 8.

10. Zur D, Neudorfer M, Shulman S, Rosenblatt A, Habot-Wilner Z: Highresolution ultrasound biomicroscopy as an adjunctive diagnostic tool for anterior scleral inflammatory disease. Acta Ophthalmol 2016; 94: e384-e389.

11. Pang X, Zhou J, Wang W, Yang W: Application of ultrasound microscope for the reattachment surgery of detachment of ciliary body. Zhonghua Yan Ke Za Zhi 1998; 34: 438-440.

12. Fine N, Pavlin CJ: Primary cysts in the iridociliary sulcus: Ultrasound biomicroscopic features of 210 cases. Can J Ophthalmol 1999; 34: 325-329.
- searching for anatomical sources of glaucoma, with a closed infiltration angle, primary and secondary glaucoma, or other causes of intraocular hypertension,

- in order to choose a method for conservative or surgical treatment,

- assessment of surgical treatment effects:

- laser operations (iridotomy, iridoplasty, suture lysis, goniopuncture, cyclophotocoagulation, capsulotomy with anterior vitreolysis in malignant glaucoma),

- fistulous and seton surgical procedures with the assessment of their patency,

- searching for causes and a documentation of glaucoma post-surgical complications.

Contraindications for UBM examinations ${ }^{(3)}$ concern the following ophthalmological cases:

- an unclosed and penetrating trauma of an eyeball;

- early post-surgical period;

- infectious inflammatory states of an eyeball surface (a relative contraindication)

- lack of patient's cooperation.

\section{Conflict of interest}

The authors do not report any financial or personal connections with other persons or organizations, which might negatively affect the contents of this publication and claim rights to it.

13. Kulig-Stochmal A, Jędrychowska-Jamborska J, Jakubowska B, Romanowska-Dixon B: Przypadek rodzinnego występowania źrenicznych cyst nabłonka barwnikowego tęczówki. Klin Oczna 2014; 116: 44-48.

14. Szpura E, Rospond-Kubiak I, Marszałek A, Kocięcki J: Demodex w obrębie dermoidu rąbka rogowki - pathogen czy przypadkowe znalezisko? Opis przypadku. Klin Oczna 2016; 118: 136-138.

15. Gündüz K, Hoşal BM, Zilelioğlu G, Günalp İ: The use of ultrasound biomicroscopy in the evaluation of anterior segment tumors and simulating conditions. Ophthalmologica 2007; 221:305-312.

16. Pavlin CJ, Vásquez LM, Lee RE, Simpson ER, Ahmed II: Anterior segment optical coherence tomography and ultrasound biomicroscopy in the imaging of anterior segment tumors. Am J Ophthalmol 2009; 147: 214-219.

17. Weisbrod DJ, Pavlin CJ, Xu W, Simpson ER. Long-term follow-up of 42 patients with small ciliary body tumors with ultrasound biomicroscopy. Am J Ophthalmol 2010; 149: 616-622.

18. Bianciotto C, Shields CL, Guzman JM, Romanelli-Gobbi M, Mazzuca D, Jr Green WR et al.: Assessment of anterior segment tumors with ultrasound biomicroscopy versus anterior segment optical coherence tomography in 200 cases. Ophthalmology 2011; 118: 1297-1302.

19. Giuliari GP, Mc Gowan HD, Pavlin CJ, Heathcote JG, Simpson ER: Ultrasound biomicroscopic imaging of iris melanoma: A clinicopathologic study. Am J Ophthalmol 2011; 151: 579-585.

20. Zhao HS, Wei WB: Dilemma in management of ocular medulloepithelioma in a child. Chin Med J 2012; 125: 392-395.

21. Romanowska-Dixon B, Jakubowska B, Markiewicz A, Pawlikowski R: Zastosowanie ultrasonografii w diagnostyce zewnątrzgałkowych nacieków czerniaka błony naczyniowej. Klin Oczna 2013; 115: 204-207.

22. Markiewicz A, Bogdali A, Romanowska-Dixon B. Rodzinne występowanie czerniaka błony naczyniowej. Klin Oczna 2014; 116: 123-126. 
23. Romanowska-Dixon B, Jakubowska B, Markiewicz A, Kowal J, Dębicka-Kumela M, Bogdali A: Diagnostyka nowotworów naczyniówki. Okulistyka 2017; 1: 14-17.

24. Padrón-Pérez N, Caminal JM, Lorenzo D, Català-Mora J: Bilateral multiple iridociliary cysts in diffuse uveal melanocytic proliferation. Can J Ophthalmol 2017; 52: 225-228.

25. Gentile RC, Berinstein DM, Liebmann J, Rosen R, Stegman Z, Tello C et al.: High-resolution ultrasound biomicroscopy of the pars plana and peripheral retina. Ophthalmology 1998; 105: 478-484.

26. Guerriero S, Ciraci L, Cardia G, Vetrugno M: Transient myopic shift as the presenting symptom of systemic lupus erythomatosus: A UBM study. Ocul Immunol Inflamm 2010; 18: 383-384.

27. Kniestedt C, Hafezi F, Seiler T: [Ultrasound biomicroscopy diagnosis of traumatic choroid effusion without cyclodialysis]. Ophthalmologe 2001; 98: 656-659.

28. Özdal PC, Mansour M, Deschênes J: Ultrasound biomicroscopic evaluation of the traumatized eyes. Eye 2003; 17: 467-472.

29. Skopiński P, Szulborski K, Struzik E, Ambroziak AM, Langwińska-Wośko E: Is it appropriate to perform anterior segment reconstruction in amblyopic eye following penetrating trauma in childhood? Wideochir Inne Tech Maloinwazyjne 2015; 10: 589-592.

30. Esposito RA, Rosati A, Manniano G, Scuderi G: Ultrabiomicroscopy anterior segment evaluation of ocular contusive trauma caused by pressurized bottled drink caps: A case report. Case Rep Ophthalmol 2018; 9: 365-368.

31. McWhae JA, Crichton AC, Rinke M: Ultrasound biomicroscopy for the assessment of zonules after ocular trauma. Ophthalmology 2003; 110: 1340-1343.

32. Khokhar SK, Pillay G, Agarwal E, Mahabir M: Innovations in pediatric cataract surgery. Indian J Ophthalmol 2017; 65: 210-216.

33. Lovisolo CF, Reinstein DZ: Phakic intraocular lenses. Surv Ophthalmol 2005; 50: 549-587.

34. Baranwal VK, Kumar S, Mishra A, Dutta AK: A study to evaluate whether CTR increases refractive unpredictability between predicted and actual IOL position. Med J Armed Forces India 2014; 70: 36-38.

35. Sewelam A, Ismail AM, Serogy H: Ultrasound biomicroscopy of haptic position after transscleral fixation of posterior chamber intraocular lenses. J Cataract Refract Surg 2001; 27: 1418-1422.

36. García-Feijoó J, Alfaro IJ, Cuiña-Sardiña R, Méndez-Hernandez C, Del Castillo JM, García-Sánchez J: Ultrasound biomicroscopy examination of posterior chamber phakic intraocular lens position. Ophthalmology 2003; 110: 163-172.

37. Mura JJ, Pavlin CJ, Condon GP, Belovay GW, Kranemann CF, Ishikawa H et al.: Ultrasound biomicroscopic analysis of iris-sutured foldable posterior chamber intraocular lenses. Am J Ophthalmol 2010; 149: 245-252.

38. Wang M, Gao Y, Li R, Wang S: Monocular lens dislocation due to vomiting - a case report. BMC Ophthal 2018; 18: 3.

39. Carassa RG, Bettin P, Fiori M, Brancato R: Nd: YAG laser iridotomy in pigment dispersion syndrome: An ultrasound biomicroscopic study. $\mathrm{Br}$ J Ophthalmol 1998; 82: 150-153.

40. Marchini G, Pagliarusco A, Toscano A, Tosi R, Brunelli C, Bonomi L: Ultrasound biomicroscopic and conventional ultrasonographic study of ocular dimensions in primary angle-closure glaucoma. Ophthalmology 1998; 105: 2091-2098.

41. Pavlin CJ, Foster FS: Plateau iris syndrome: Changes in angle opening associated with dark, light, and pilocarpine administration. Am J Ophthalmol 1999; 128: 288-291.

42. Guo S, Gewirtz M, Thaker R, Reed M: Characterizing pseudoexfoliation syndrome through the use of ultrasound biomicroscopy. J Cataract Refract Surg 2006; 32: 614-617.

43. Kosmala J, Czechowicz-Janicka K: Przydatność badania ultrabiomikroskopowego (UBM) w diagnostyce oraz ocenie skuteczności leczenia operacyjnego jaskry. Ulrasonografia 2006; 26: 33-40.

44. Kumar RS, Baskaran M, Chew PTK, Friedman DS, Handa S, Lavanya $\mathrm{R}$ et al.: Prevalence of plateau iris in primary angle closure suspects an ultrasound biomicroscopy study. Ophthalmology 2008; 115: 430-434.

45. Mannino G, Verrilli S, Calafiore S, Ciarnella A, Cutini A, Mannino C et al.: Evaluation of recurrent hyphema after trabeculectomy with ultrabiomicroscopy 50-80 MHz: A case report. BMC Res Notes 2012; 5: 549.

46. Detorakis ET, Stojanovic N, Chalkia A, Pallikaris IG: EX-PRESS implant position and function: comparative evaluation with ultrasound biomicroscopy and optical coherence tomography. Middle East Afr J Ophthalmol 2016; 23: 110-114.

47. Potop V, Corbu C: The role of clear lens extraction in angle closure glaucoma. Rom J Ophthalmol 2017; 61: 244-248. 